\title{
Is the prevalence of nutritional screening time-dependant? Results of a cross-sectional survey in a teaching hospital in London
}

\author{
A. Fikree, A. Kramer, A. Prabhakar, C. Soulsby, J. Powell-Tuck and M. Glynn \\ Department of Gastroenterology, Royal London Hospital, London E1 1BB, UK
}

Current NICE guidelines recommend routine screening for every patient who is admitted to hospital ${ }^{(1)}$. Screening tools, such as the MUST, use a combination of weight, height, BMI, percentage unintentional weight loss and the presence of illness. Nationwide studies and audits have demonstrated that rates of screening remain low, and at best reach a value of about $70 \%{ }^{(2)}$. Our study aimed to find out whether the rates of screening varied with duration of hospital stay.

A cross-sectional survey was carried out at the Royal London Hospital on 28 March 2009. Out of 469 adult patients who were in the hospital that day, 279 patients were on the general and acute medical and surgical wards. All 279 had their notes, drug charts and observation charts assessed for the presence of weight, height and BMI documentation, and for evidence of ongoing nutritional monitoring by way of food and weight charts. Patients were then asked whether they had noticed any unintentional weight loss prior to admission. Thirty six patients could not report due to not being by bed, language barriers or being medically unwell, leaving 243 patients who selfreported.

The comparison of nutritional screening and monitoring by length of hospital stay is shown in Table 1 below.

\begin{tabular}{lccc}
\hline & $\begin{array}{c}<1 \text { week }-149 \text { patients } \\
\text { (number, percentage) }\end{array}$ & $\begin{array}{c}1-4 \text { weeks }-86 \text { patients } \\
\text { (number, percentage) }\end{array}$ & $\begin{array}{c}>4 \text { weeks }-44 \text { patients } \\
\text { (number, percentage) }\end{array}$ \\
\hline Weight measured? & $48,32 \%$ & $41,48 \%$ & $20,45 \%$ \\
Weight and height measured? & $15,10 \%$ & $11,13 \%$ & $3,7 \%$ \\
BMI $<20$ & $1,0.7 \%$ & $1,1 \%$ & $1,2 \%$ \\
Up to date food chart present? & $14,9 \%$ & $19,22 \%$ & $19,22 \%$ \\
Up to date nutritional chart present? & $14,9 \%$ & $30,35 \%$ & $12,27 \%$ \\
Number who self-reported & $132,86 \%$ & $78,91 \%$ & $33,75 \%$ \\
Percentage unintentional weight loss & $45,34 \%$ & $33,42 \%$ & $21,64 \%$ \\
\hline
\end{tabular}

Patients who are in hospital between 1 and 4 weeks are more likely to be screened and monitored compared with patients who are in hospital for less than 1 week or more than 4 weeks. This may reflect the wishes of doctors asking for patients to be weighed or increased opportunity for measurement of weight. The decrease in nutritional screening and monitoring after 4 weeks may reflect that these patients who stay in hospital longer are more ill, and more difficult to be weighed. These patients were more likely to have a low BMI and unintentional weight loss and are therefore at greater risk of malnutrition.

We have previously shown that BMI is difficult to measure in acute illness, particularly at the time of admission ${ }^{(3)}$. A duration of 4 weeks, however, provides many more opportunities for nutritional screening, and there should be no excuse for not doing it, particularly as these patients are the ones at even greater risk of malnutrition. Difficulties in measuring BMI can be overcome by using mid upper arm circumference measurements, as this has been shown to correlate with BMI and predicts poorer outcome better.

1. Nutritional Support in Adults: Oral Nutrition Support, Enteral Tube Feeding and Parenteral Nutrition NICE 2006. http://guidance.nice.org.uk/CG32/ Guidance/pdf/English

2. Campbell SE, Avenall A \& Walker AE (2002) QJ Med 55 83-87.

3. Powell-Tuck J \& Hennessy EM (2003) Clin Nutr 22, 307-312. 